University of Montana

ScholarWorks at University of Montana

3-2009

\title{
Functional Differences Within a Guild of Tropical Mammalian Frugivores
}

Jedidiah F. Brodie

Olga E. Helmy

Warren Y. Brockelman

John L. Maron

University of Montana - Missoula, john.maron@mso.umt.edu

Follow this and additional works at: https://scholarworks.umt.edu/biosci_pubs

Part of the Biology Commons

Let us know how access to this document benefits you.

\section{Recommended Citation}

Brodie, Jedidiah F.; Helmy, Olga E.; Brockelman, Warren Y.; and Maron, John L., "Functional Differences Within a Guild of Tropical Mammalian Frugivores" (2009). Biological Sciences Faculty Publications. 322. https://scholarworks.umt.edu/biosci_pubs/322

This Article is brought to you for free and open access by the Biological Sciences at ScholarWorks at University of Montana. It has been accepted for inclusion in Biological Sciences Faculty Publications by an authorized administrator of ScholarWorks at University of Montana. For more information, please contact scholarworks@mso.umt.edu. 


\title{
Functional differences within a guild of tropical mammalian frugivores
}

\author{
Jedediah F. Brodie, ${ }^{1,3}$ Olga E. Helmy, ${ }^{1}$ Warren Y. Brockelman, ${ }^{2}$ and John L. Maron ${ }^{1}$ \\ ${ }^{1}$ Division of Biological Sciences, University of Montana, Missoula, Montana 59812 USA
${ }^{2}$ Center for Conservation Biology, Institute of Science and Technology for Research and Development, Mahidol University, \\ Salaya, Phuttthamonthon 4 Road, Nakhon Pathom 73170 Thailand
}

\begin{abstract}
Many plants interact with groups of mutualist pollinators and seed dispersers. A key issue for both basic ecology and conservation is whether the different species within these guilds of mutualist animals are functionally equivalent. Comparing the relative effects of sympatric mutualists is important for understanding the evolution of multispecies mutualisms and for predicting mutualism stability in the face of anthropogenic change. However, empirical comparisons of the population-level impacts of mutualist animals on their host plant are rare, particularly for seed dispersal mutualisms in species-rich ecosystems. We compared the influence of three seed-dispersing tropical mammals, lar gibbons (Hylobates lar), sambar deer (Rusa unicolor), and red muntjac deer (Muntiacus muntjak), on the demography of a shared host tree in Thailand, Choerospondias axillaris (Anacardiaceae). Sambar and muntjac dispersed far more $C$. axillaris seeds than did gibbons. While sambar deposited many seeds under female tree canopies, muntjac were the only disperser to move seeds to open microhabitats, where $C$. axillaris seed germination, seedling survival, and initial growth are enhanced. Using stage-based population models, we assessed how disperser-specific seed dispersal, variation in the frequency of canopy gap formation, and their interaction influenced the potential population growth of $C$. axillaris. Large differences in dispersal quantity and small differences in dispersal quality among sambar and gibbons resulted in similar and negligible impacts on the tree's population dynamics. Muntjac, by taking some of the seeds to open microhabitats, are projected to have a greater positive impact on $C$. axillaris demography than either sambar or gibbons. Model comparisons of population-level species impacts may allow us to predict which ecological interactions are at risk from loss of critical species.
\end{abstract}

Key words: biodiversity; Choerospondias axillaris; demography; dispersal effectiveness; gap dynamics, gibbons; muntjac deer; mutualism; redundancy; sambar deer; seed dispersal; tropical seasonal forests, Thailand.

\section{INTRODUCTION}

Mutualistic interactions are widespread in nature (Bronstein 1994, Ness et al. 2006). Historically, consideration of mutualisms has centered on highly specialized and tightly coevolved interactions where a single species interacts with only one partner (Stanton 2003). Yet it is increasingly clear that most mutualisms are more complex, often involving networks of interacting species. Presently, we lack a comprehensive understanding of how the different species within these mutualist guilds compare in the overall effects on their host (Waser et al. 1996, Stanton 2003). That is, do different mutualist partners have different impacts on host fitness or abundance, or are mutualists in the same guild functionally similar? Answers to these key questions remain elusive (Stanton 2003, Howe and Miriti 2004).

Manuscript received 18 January 2008; revised 9 June 2008; accepted 16 June 2008. Corresponding Editor: T. P. Young.

${ }^{3}$ Present address: David H. Smith Conservation Research Fellow, P.O. Box 128, Gardiner, Montana 59030 USA. E-mail: jedediah.brodie@gmail.com
Determining the relative benefits that different mutualists provide to their host is essential for understanding how multiple-species mutualist assemblages are maintained, given the potential for competition among the mutualists (Palmer et al. 2008). Distinguishing the relative costs and benefits of associations with particular mutualists can also shed light on whether hosts can select for those mutualists that are most beneficial (Yu et al. 2001, Palmer et al. 2003). Finally, quantifying the relative effectiveness of different mutualist partners can elucidate how changing ecological context (Bronstein 1994) may influence the spatial mosaic of the coevolution of mutualistic traits (Gomulkiewicz et al. 2003).

In this paper we are particularly interested in how different mutualist partners may similarly or differentially influence the population dynamics of their host. This is of critical importance to conservation. Since species loss from mutualist guilds is an increasingly recognized problem (Cordeiro and Howe 2001, Peres and Palacios 2007), it is imperative that we understand whether particular species have disproportionately strong effects on their host (Christian 2001). Plant- 
disperser systems are excellent cases for comparing the relative effectiveness of different mutualist partners because seed dispersers usually differ in both dispersal quantity and quality (sensu Schupp 1993). For a given plant species, some animals may remove more fruit (Howe and Vande Kerckhove 1981), disperse seeds farther (Russo et al. 2006, Jordano et al. 2007), take seeds to better microhabitats (Reid 1989), be more effective at seed scarification (Figuerola et al. 2002), or destroy fewer of the seeds that they consume (Jordano 1983). Yet we know surprisingly little about whether this variation in dispersal effectiveness has meaningful effects on plant demography, abundance, or population dynamics. Most seed-dispersal studies have not quantified how variation in dispersal effectiveness influences plant abundance or dynamics (Howe and Miriti 2004). In one of the only studies that has explored populationlevel effects of different dispersers of the same plant, the "effectiveness" (relative abundance $x$ visitation rate $x$ seed handling $\times$ probability of safe-site deposition) of a bat species in dispersing a Mexican columnar cactus was 4-5 orders of magnitude greater than that of four avian seed dispersers (Godinez-Alvarez et al. 2002). Yet the modeled cactus population growth rate attributable to each of the five animal species differed only slightly because of the high variability and low elasticity of seed dispersal relative to other vital rates (Godinez-Alvarez et al. 2002). Thus the relationship between disperser effectiveness and relative impacts on plant population dynamics is not necessarily straightforward (GodinezAlvarez and Jordano 2007).

Assessing the relative effectiveness of different mutualist partners is especially critical in the tropics because many plants rely on multiple seed-dispersing species (Estrada and Fleming 1986, Bascompte and Jordano 2007). Moreover, many tropical frugivores are at risk of extinction from habitat loss and fragmentation (Cordeiro and Howe 2001) as well as overhunting (Peres and Palacios 2007). In the simplest case, plants that lose their sole disperser species can clearly be negatively affected demographically (Traveset and Riera 2005). But for the more common case, where plants are dispersed by several or many frugivore species (Bond 1995), it is unclear how loss of any one frugivore species might affect host-plant abundance. The general issue of whether diversity within frugivore mutualist assemblages buffers host plants from the negative effects of loss of any single mutualist species remains an open question.

In this study, we compare the demographic effects of seed dispersal by gibbons (Hylobates lar), red muntjac deer (Muntiacus muntjak), and sambar deer (Rusa unicolor; syn. Cervus unicolor) on the canopy tree Choerospondias axillaris (Roxb.) Burtt \& Hill (Anacardiaceae) in tropical seasonal forest of Thailand. We quantified how these three dispersers vary in the effectiveness of their seed dispersal by determining both the quantity of seeds they disperse and the microhabitat into which they bring seeds. We then assessed how variation in dispersal effectiveness affects $C$. axillaris abundance by combining results from observations, demographic monitoring, and experiments into a stagedbased matrix model of $C$. axillaris population growth. This approach is fairly novel in two respects. First, ours is one of the few attempts to model how variation in dispersal effectiveness that influences seed and seedling fate translates into long-term changes in plant population growth. Second, like many tropical trees (Whitmore 1989), C. axillaris recruitment may depend on forest canopy gaps; thus the potential effects of dispersers cannot be fully assessed without an understanding of gap dynamics. Therefore, we combine our stage-based population model with a separate matrix model that depicts realistic rates of canopy-gap formation and subsequent fill-in. This enabled us to put seed dispersal in a biologically realistic context and explore how dispersal may interact with microhabitat dynamics to influence the demographic impacts of each disperser.

\section{Methods}

\section{Study area and species}

Khao Yai National Park $\left(14^{\circ} 26^{\prime} \mathrm{N}, 101^{\circ} 22^{\prime} \mathrm{E} ; 2166\right.$ $\mathrm{km}^{2}$ ) straddles a large plateau, approximately 700-900 $m$ elevation, with seasonal evergreen or mixed evergreen-deciduous forest types throughout most of the area and mixed deciduous forest on the steep edges (Smitinand 1977). Mean annual rainfall is $\sim 2200 \mathrm{~mm}$, mostly occurring during May-October; there is a pronounced dry season from November through April. Abundances of many large-mammal species in the central portion of the park is high (Lynam et al. 2006). A 30-ha "forest-dynamics" plot was established in 1993 in the central western portion of the park; all woody stems $\geq 1 \mathrm{~cm}$ in diameter at breast height $(\mathrm{dbh} ; 130 \mathrm{~cm})$ have been mapped, marked, and identified. The plot contains 200 tree species $\geq 10 \mathrm{~cm} \mathrm{dbh}$, where Choerospondias axillaris is the 24 th most abundant by density ( $1.2 \%$ of trunks $\geq 10 \mathrm{~cm} \mathrm{dbh}$ ), and third most abundant by cumulative basal area (5.9\% of total; W. Y. Brockelman, unpublished data). The plot contained 159 adult $C$. axillaris, of which 59 trees were female.

Choerospondias axillaris (syn. Spondias axillaris Burtt $\&$ Hill) is a large (up to $30 \mathrm{~m}$ tall) canopy tree widely distributed in tropical Asia. It is dioecious and females bear fruits from June through October; the fruits are 2-3 $\mathrm{cm}$ long, and are composed of a pericarp surrounding fibrous, watery flesh, with a single stone inside $\sim 1.9 \times 1.4$ $\mathrm{cm}$ in size. Each stone (hereafter "seed") has a very hard covering over five embryos. In Khao Yai, fruits are consumed almost entirely by gibbons, sambar, and red muntjac (Kunsakorn 2001, this study). While rodents consume some fruits and may perform primary or secondary dispersal of seeds, relatively few seeds are dispersed by rodents relative to total fruit production (see Results: Seed dispersal ..., below). C. axillaris is often present in early successional habitats, and may be dependent on gaps for seedling survival, but persists into 
mature mixed-evergreen seasonal forest. C. axillaris is highly unusual among tropical Asian trees in that its fruits drop off the tree when ripe rather than hanging on until eaten or rotten (Corlett 1996). Moreover, fruits and seeds are too large to be dispersed by most birds, and the fibrous pulp adheres strongly to the seed coat, a fruit anatomy not favored by hornbills (Bucerotidae; P. Poonswad, personal communication). These may be "partner selection mechanisms" (sensu Stanton 2003) whereby the tree promotes consumption of its fruits by terrestrial, non-volant frugivores. We explored this possibility by comparing the seed dispersal effectiveness of arboreal gibbons (Hylobates lar) and two species of terrestrial deer, sambar and red muntjac. Gibbons consume $C$. axillaris fruits before they fall and later defecate the seeds. Gibbons are common in much of Khao Yai; the forest-dynamics plot includes the entire home range of one group of animals ("Group A" composed of two adults plus, generally, two other individuals usually, but not always, their young) that have been studied since 1980 and are habituated to the presence of researchers. Sambar and red muntjac are large (109-260 kg) and small $(20-28 \mathrm{~kg})$ deer, respectively, that are distributed widely across tropical Asia. Muntjac density in the vicinity of the forest-dynamics plot during the time of this study was estimated at $0.7-$ 4.2 deer $/ \mathrm{km}^{2}$ (Lynam et al. 2006); no such data are available for sambar. Both deer species primarily consume foliage, but they also eat large quantities of $C$. axillaris fallen fruit when available. Deer regurgitate "cleaned" C. axillaris seeds, usually while bedding and ruminating (W. Y. Brockelman and J. F. Brodie, personal observations). Although dispersal of undispersed fallen fruit is often considered secondary dispersal (Howe and Smallwood 1982), we treat it here as primary dispersal because of the tree's unique trait of dropping fruits when ripe, possibly to attract terrestrial dispersers.

Seeds of $C$. axillaris fall or are dispersed during the monsoon season (July-November), and remain on the ground to germinate the following wet season; we have detected no seed bank (see Results: Seed dispersal ..., below). The seeds germinate equally well whether they are defecated by gibbons, regurgitated by deer, or the fruits are uneaten (Kunsakorn 2001); variance in germination is mainly due to microhabitat differences among deposition sites (see Results: Seed dispersal ..., below). Seeds are sufficiently large, conspicuous, and easily identifiable that they can be sampled with transects rather than seed traps.

\section{Field sampling}

We established 15 belt transects $(500 \times 4 \mathrm{~m}$ each $)$ across the forest-dynamics plot (accounting for $10 \%$ of the plot). We surveyed these transects weekly for 10 weeks from mid-July to September in 2003 and 2004. We recorded the number of dispersed $C$. axillaris seeds, the number of seeds in the pile in which they had been deposited, and the identity of the disperser. Disperser identity was easily determined because gibbons defecate seeds whereas deer regurgitate them. The identity of the deer species that dispersed seeds could be determined by the size of tracks and scat. Because fieldwork took place during the rainy season, the forest floor stayed continually moist and deer tracks could generally be found under the leaf litter. The quantity of seeds dispersed by deer and the microhabitats to which all frugivores dispersed seeds were measured from these transect data. The deer deposited very shiny piles of regurgitated seeds and we are confident that, with our regular sampling, we missed very few deer-dispersed seeds. Gibbon-defecated seeds, however, were somewhat less conspicuous. Therefore we assessed the quantity of seeds dispersed by gibbons by following individuals all day for 5-6 days per month and recording exactly how many $C$. axillaris seeds were defecated. To calculate the total number of seeds dispersed by gibbons on the plot during the study period, we divided the total number of seeds dispersed by single gibbons on observation days by the proportion of the study period during which observations took place and multiplied by the estimated mean number of gibbons on the plot at any one time.

We measured seed germination and predation experimentally to determine how canopy cover, seed-pile size, and being under an adult female $C$. axillaris canopy influenced the seed-to-seedling transition. We treated "under adult female canopy" as a separate microhabitat because it was nearly always high canopy cover, yet could also have had elevated seed and seedling mortality from seed-predator attraction or host-specific pathogens (cf. Janzen 1970, Connell 1971). In 2003 and 2004 we set up closed wire cages $(30 \times 30 \times 15 \mathrm{~cm}$ wire exclosures pinned to the ground) with arrays of seeds at four densities $(2,8,30$, or 100 seeds/pile, which spans the range of observed deposition-pile sizes). These arrays were replicated across 15 sites that spanned the range of forest canopy-cover conditions; one third of sites were under adult female canopies (total of 2100 seeds/yr). The mesh size of the closed cages was $\sim 1 \mathrm{~cm}^{2}$, which excluded vertebrate seed predators but not small insects or fungi. Previous work in Khao Yai has shown that seed handling (i.e., fruit pulp intact vs. defecation by gibbons vs. regurgitation by deer) does not affect germination (Kunsakorn 2001), so we did not test this effect further in this study. In order to examine rates of post-dispersal seed predation, we repeated the seedaddition experiment described above, at the same sites, using "open" cages (same wire mesh as above but in a 3$\mathrm{cm}$-tall ring surrounding the seeds; total of 2100 seeds/yr). The open cages prevented the seeds from rolling away but allowed access by seed predators.

The numbers of seedlings in closed cages and remaining seeds in open cages were recorded the year following the initiation of each experiment. We performed multiple logistic regressions of seed-pile size, canopy-cover proportion (see below), and female canopy (a binary measure of whether the site was under 
a fruiting adult) vs. germination (closed cages) and seed removal rates (open cages). We report $R^{2}$ values for full multiple linear-regression models, log-likelihood (LL) values for multiple logistic regressions (both significant at $\alpha=0.05$ ), and both individual parameter coefficients $(\beta)$ and partial $P$ values.

To assess whether removed seeds were secondarily dispersed or destroyed by small mammals, we set out piles of 10 seeds at each planting-array site in each year (200 seeds each year), to which we had glued $60 \mathrm{~cm}$ of thin nylon string (cf. Forget and Milleron 1991). We returned 14 days later and scoured a 5-m-radius circle around the point where the pile had been placed, looking for strings, which we followed to the attached seeds to determine whether they had been destroyed or were still intact.

We marked all naturally occurring seedlings on the transects ( $N=670$ seedlings) and measured their survival and growth from 2003-2004 and 2004-2005. We assessed the effects of canopy cover, height, and mother-tree canopy on seedling survivorship using multiple logistic regressions and on seedling growth using linear multiple regressions.

Individuals of $C$. axillaris $>1.3 \mathrm{~m}$ tall but smaller than $18 \mathrm{~cm}$ dbh were considered juveniles, those $>18 \mathrm{~cm} \mathrm{dbh}$ were defined as adults, as this was the smallest size of any observed fruiting tree. Juvenile survival and growth and adult survival were measured from repeat censuses of all marked individuals on the entire 30 -ha plot. We estimated tree fecundity by visual counts (with $8 \times 40$ binoculars) of fruit crop at the beginning of the fruiting season in a random sample ( $N=14$ trees) of the total adult female population. We also measured the proportion of the total fruit crop that had dropped or been dispersed during the field season by repeating these visual counts (and counting seeds on the ground under the canopies) at the end of the field season. We compared fruit crop between years, and assessed its relationship to tree diameter using multiple linear regressions.

We measured canopy cover at all naturally dispersed seed piles with hemispherical canopy photographs, at locations where we found seedlings on transects, and at sites where we placed experimental seed arrays. All photographs were taken $1 \mathrm{~m}$ above the ground and analyzed for canopy-cover proportion using HemiView 2.1 (Delta-T Devices, Cambridge, UK). To assess the change in forest cover over time, we set up 218 permanent photo points across a range of canopy conditions on 10 of the 15 transects. At each, we took hemispherical canopy photos every year, 2003-2005. We then constructed an annual transition matrix for microhabitat types.

\section{Population model}

We used female-only, post-birth census, stage-based matrix projection models to assess the influence of seed dispersers on the population dynamics of C. axillaris. This model includes both demographic transitions for $C$. axillaris and transitions among microhabitat states, since forest microhabitat is dynamic through time and the demographic performance of $C$. axillaris is enhanced in light gaps. We used six stage-microhabitat classes: seedlings underneath female canopies, seedlings with $11-$ $30 \%$ canopy cover, seedlings with $31-70 \%$ canopy cover, seedlings with $71-100 \%$ canopy cover, juveniles $(>1.3 \mathrm{~m}$ tall but $<18 \mathrm{~cm} \mathrm{dbh})$, and adults $(>18 \mathrm{~cm} \mathrm{dbh})$. No points in the forest had less than $11 \%$ canopy cover. The seedling-stage boundaries were based on graphical inspection of the relationships between canopy cover and germination and seedling survivorship (cf. Morris and Doak 2002). Most (98\%) of the microhabitat underneath adult females was in the $71-100 \%$ canopycover range, but this was considered a separate class because seedling survivorship was significantly lower (see Results: Seed dispersal..., below). Only adults reproduced, with fecundity estimated from measured fruit crops at the beginning of the two fruiting seasons. Seed dispersal to different microhabitats by different frugivores was measured from the transect data and expressed as a proportion of the total fruit crop available to the frugivores during the study period (i.e., total fruit crop produced minus the proportion of seeds remaining on or underneath the trees at the end of the study period). All vital rates were calculated from data pooled across years.

We used the microhabitat transitions probabilities measured from the repeat canopy photographs to construct a microhabitat transition matrix $(\mathbf{C})$, rescaled so that each column summed to 1 . Seedlings could "move" among microhabitats via gaps opening up or closing in above them, measured by microhabitat transition probabilities, $C_{i j}$. Gap formation was modeled to occur at a predictable time of year (cf. Pascarella and Horvitz 1998), specifically at the end of the rainy season (August-October) when winds increase (W. Y. Brockelman, personal observation). Therefore the order of events in the model was: seed dispersal $>$ microhabitat transition $>$ germination, seedling survivorship, and seedling growth. Germination, seedling survivorship, and seedling growth were measured at the median canopy-cover values for each microhabitat, using logistic (germination and seedling survival) or linear (seedling growth) regressions of each vital rate vs. canopy cover. We multiplied seed removal by the proportion of the removed seeds that had been predated (from the string experiments), to estimate total seed predation probabilities. Annual seedling-to-juvenile transition probabilities ( Trans $_{j, j u v}$ ) were measured as microhabitat-specific seedling growth (in vertical centimeters; from linear regressions of seedling growth vs. canopy cover) accounting for size structure within the seedling stages (cf. Crouse et al. 1987):

$$
\operatorname{Trans}_{j, j \mathrm{uv}}=\frac{\left(\operatorname{Surv}_{j}^{\left.\left(\mathrm{SG}_{j} / \mathrm{Hgt}\right)^{-1}\right)}\right) \times\left(1-\operatorname{Surv}_{j}\right)}{1-\operatorname{Surv}_{j}^{\left(\mathrm{SG}_{j} / \mathrm{Hgt}\right)}}
$$


where $\mathrm{SG}_{j}$ and $\mathrm{Surv}_{j}$ are growth (in vertical centimeters) and annual survivorship, respectively, of seedlings in microhabitat $j$, and $\mathrm{Hgt}$ is the height cutoff between seedlings and juveniles $(1.3 \mathrm{~m})$.

Vital rates for juveniles and adults were independent of microhabitat, partly due to lack of microhabitatspecific data for these classes, and also because "canopy cover" loses much of its meaning for an adult tree that is itself part of the canopy. We therefore calculated transition of juveniles to adults using a formula identical to Eq. 1 except substituting juvenile growth (measured as centimeters in diameter) and survivorship for the seedling equivalents, and using a diameter stage boundary $(18 \mathrm{~cm}$ ) between juveniles and adults. (See Appendix A for details of model construction.)

We assessed the influence of the frugivore species (alone and all three combined) on C. axillaris population dynamics. For each of 10000 bootstrap iterations we resampled (with replacement) the raw data to estimate vital rates and constructed five population projection matrices that differed only in the seed-dispersal term (i.e., no dispersal, gibbon dispersal, muntjac dispersal, sambar dispersal, and dispersal by all frugivores combined). We then estimated the difference in $C$. axillaris lambda $(\Delta \hat{\lambda})$ for dispersal by each frugivore vs. no dispersal at all, and generated $95 \%$ bootstrap confidence intervals around these differences.

\section{RESUlts}

Seed dispersal and Choerospondias axillaris demography

Of the 8202 seeds naturally dispersed in 103 piles across both years, we could confidently identify the disperser for $79.6 \%$ of piles and $95.8 \%$ of total seeds. For these, all of the seeds were dispersed by gibbons, muntjac, and sambar except 22 seeds $(0.3 \%$ of total) that were dispersed by a bear (Ursus thibetanus or Helarctos malayanus), 3 seeds $(<0.1 \%)$ by an elephant (Elephas maximus), and 7 seeds $(0.1 \%)$ by a civet (Viverridae). Handling by rodents was also evident in $1.4 \%$ of seeds, but it is unclear whether this represents primary or secondary dispersal. Of the dispersed seed piles where we could not definitively identify the disperser species (4.2\% of total seeds), $37 \%$ were dispersed by deer (based on the shiny regurgitated seeds). However, due to a lack of distinct tracks (or tracks of both deer species) near the seeds we could not identify the species of deer.

The three frugivores differed in the quantity of $C$. axillaris seeds dispersed (ANOVA: $F_{2,3}=171.37, P<$ $0.01)$. Muntjac and sambar dispersed more seeds than gibbons (Tukey post hoc comparisons: $P<0.01$ ), but there were no significant differences in dispersal quantity between the two deer $(P=0.27$; Fig. 1). There were no significant differences between years in the proportions of seeds dispersed to the different microhabitats for gibbons $\left(\chi_{3}^{2}=0.51, P=0.92\right)$, muntjac $\left(\chi_{3}^{2}=0.02, P=\right.$ $0.99)$, or sambar $\left(\chi_{3}^{2}=0.16, P=0.98\right)$. Seeds were dispersed to different microhabitats roughly in propor- tion to the availability of those microhabitats for gibbons $\left(\chi_{3}^{2}=1.31, P=0.73\right)$ and muntjac $\left(\chi_{3}^{2}=0.37\right.$, $P=0.95)$. Sambar dispersed more seeds than expected by chance to the "underneath adult female canopy" microhabitat and fewer than expected to the other three microhabitats $\left(\chi_{3}^{2}=8.65, P=0.03\right)$. A majority of sambar-dispersed seeds were found under female $C$. axillaris, whereas muntjac and gibbons dispersed most of their seeds away from female canopies to forest in the 31-70\% canopy-cover range (also see Appendix B). Muntjac were the only dispersers to deposit seeds in the two highest-light microhabitats (Fig. 1).

Fruit crop at the beginning of the fruiting season did not differ significantly between years (linear regression: $\left.R^{2}=0.11, \mathrm{df}=24, P=0.75\right)$, and was not significantly related to tree diameter ( $\beta$ [individual parameter coefficient $]=-11.84, P=0.13)$. Fruit production was $801 \pm 106($ mean $\pm \mathrm{SE})$ fruits per tree; on average $70.8 \%$ $\pm 4.1 \%$ of seeds produced were dispersed by the end of the field season (i.e., were not still on or underneath the canopy). The percentage of seeds that were dispersed did not vary significantly between years (linear regression: $\left.R^{2}=0.09, \mathrm{df}=24, P=0.21\right)$ or as a function of tree diameter $(\beta=0.00, P=0.49)$.

Germination in experimental seed piles was negatively affected by canopy cover $(\beta=-3.75, P<0.01$; see Fig. 2) and was significantly higher in 2003 than in 2004 (logistic regression: $\log$ likelihood $(\mathrm{LL})=-148.8, \mathrm{df}=$ 2009, $P=0.04)$. However, seed germination was not significantly affected by seed pile size $(\beta=0.00, P=0.24)$ or by being under an adult-female canopy $(\beta=-12.02, P$ $=0.82$ ). While germination under female trees was zero in our trials, this is at least partly an experimental artifact since seedlings do occur under female canopies in nature. All 2003 seeds that did not germinate and were not removed by $2004(N=3350$ seeds $)$ were monitored for the following year, and none germinated. Percentages of seeds removed from the open cages were $34 \% \pm 5 \%$ and $37 \% \pm 6 \%$ (mean $\pm \mathrm{SE}$ ) for 2003 and 2004 , respectively ( $N=2100$ seeds in each year); seed removal was not significantly affected by canopy cover, being under a female canopy, or seed-pile size. Postdispersal seed predation was not significantly affected by canopy cover or location under a female canopy. Of removed seeds with strings attached, $80 \% \pm 13 \%$ and $84 \% \pm 6 \%($ mean $\pm \mathrm{SE})$ were recovered within $5 \mathrm{~m}$ in 2003 and 2004, respectively. Of these recovered seeds, the percentages of post-removal seed predation were $86 \% \pm 14 \%$ and $64 \% \pm 11 \%$ in 2003 and 2004 , respectively.

Seedling survivorship was negatively affected by canopy cover $(\beta=-3.75, P=0.01$; Fig. 2$)$ and by being under an adult female canopy $(\beta=-0.89, P=0.01)$, but not by seedling height $(\beta=0.03, P=0.28$ ). Seedling survivorship (logistic regression: $\mathrm{LL}=-212.4, \mathrm{df}=580$, $P=0.99$ ) and growth (linear regression: $R^{2}=0.07, \mathrm{df}=$ $90, P=0.17)$ did not differ significantly between years. Seedling growth, however, was significantly negatively 


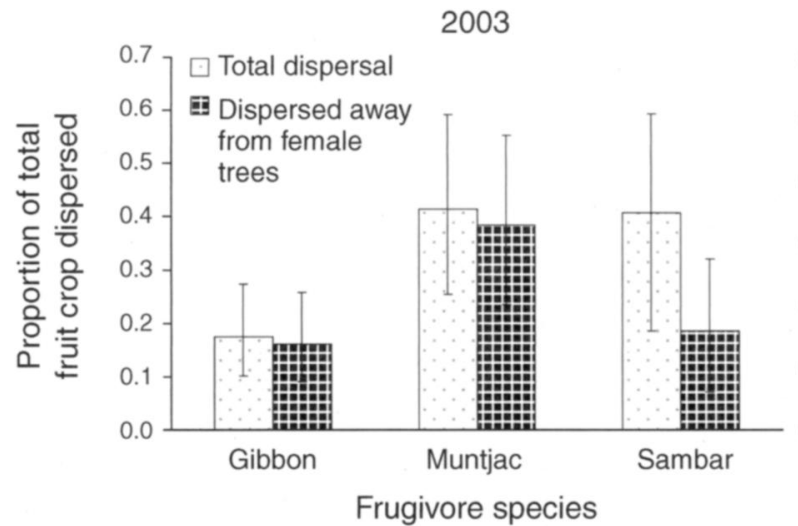

Frugivore species

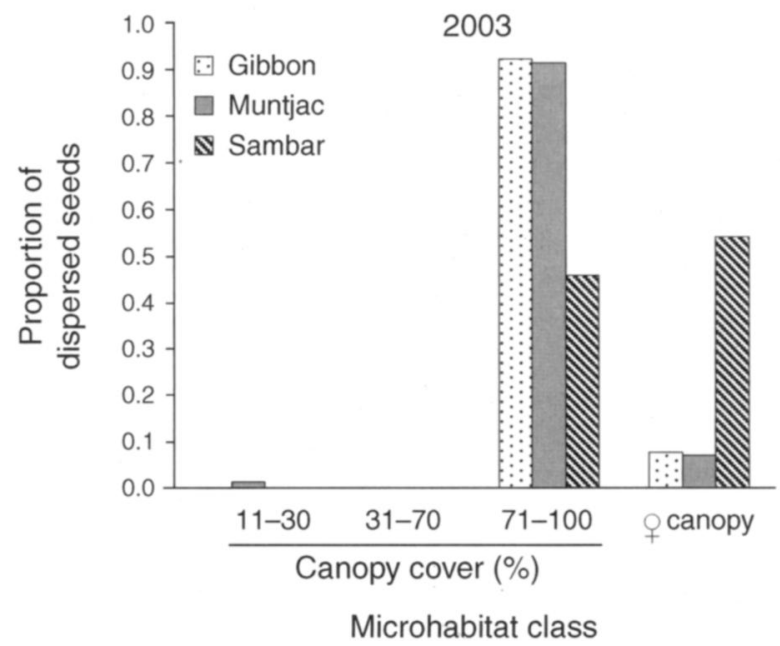

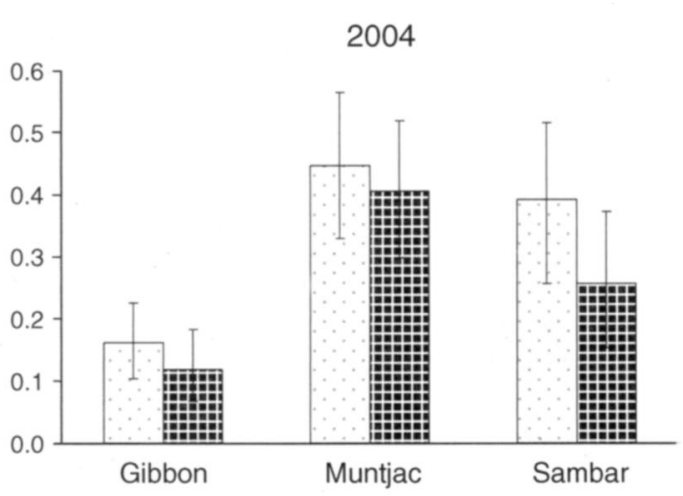

Frugivore species

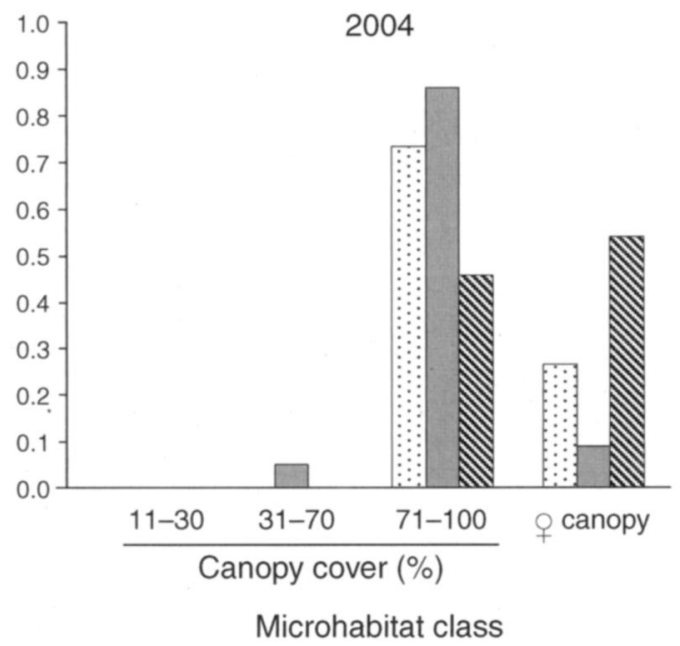

FIG. 1. (Top panels) Relative seed dispersal by each frugivore, expressed as a proportion of total fruit crop on the plot across two years. Error bars show $95 \%$ bootstrap confidence intervals. (Bottom panels) Deposition microhabitats of dispersed seeds across two years.

associated with increasing canopy cover $(\beta=-11.58, P=$ 0.01 ; Fig. 2$)$, but not by seedling height $(\beta=0.08, P=$ 0.36 ). Presence under an adult female canopy did not significantly affect seedling growth $(\beta=0.93, P=0.53)$, but only 16 seedlings under female canopies survived (both yearly transitions combined), so we had low power to detect this effect.

Of the 15 juvenile $C$. axillaris on the Khao Yai forestdynamics plot in 2002, 14 trees $(93.3 \%)$ survived to the re-census three years later, resulting in a mean annual survivorship estimate of 0.98 . Juvenile tree diameter did not significantly affect survivorship (logistic regression: $\mathrm{LL}=0.00, \mathrm{df}=14, \beta=37.35, P=0.84$ ) or growth (linear regression: $\left.R^{2}<0.01, \mathrm{df}=14, \beta=0.01, P=0.93\right)$. Juvenile growth was $1.89 \mathrm{~cm} \pm 0.43 \mathrm{~cm} / \mathrm{yr}$ (mean \pm SE). Of the 159 adults on the plot at the first census, 152 adults $(95.6 \%)$ survived to the re-census; estimated mean annual survivorship was 0.99 . Adult tree diameter did not significantly affect survivorship (logistic regression: $\mathrm{LL}=-27.75, \mathrm{df}=158, \beta=0.03, P=0.19)$ or growth (linear regression: $R^{2}<0.01, \mathrm{df}=158, \beta=0.01, P=$ $0.71)$.

\section{Gap dynamics}

Forest cover across the biodynamics plot ranged from $11 \%$ to $98 \%$. Forest canopy in gaps can increase over time as they fill in with vegetation, or decrease as wind continues to knock down trees and branches on their edges. Repeat canopy photography at permanent photo points revealed that overall the forest canopy cover is slowly increasing. Excluding the female-canopy microhabitat (with a canopy cover of $0.89 \pm 0.06$ [mean \pm $\mathrm{SD}]$ ), the majority of photography points showed increases in canopy cover as they filled in with vegetation.

\section{Population model}

We first asked how the microhabitat into which seeds were dispersed might affect $C$. axillaris population growth. Here we assumed an unchanging microhabitat with no inherent gap dynamics. In this case, canopy cover significantly influenced $C$. axillaris populationgrowth rates. $\hat{\lambda}$ was higher in the $11-30 \%$ canopy-cover microhabitat $(1.123 \pm 0.042)$ than in the $31-70 \%, 71-$ $100 \%$, and "under female canopy" microhabitats $(0.985$ 

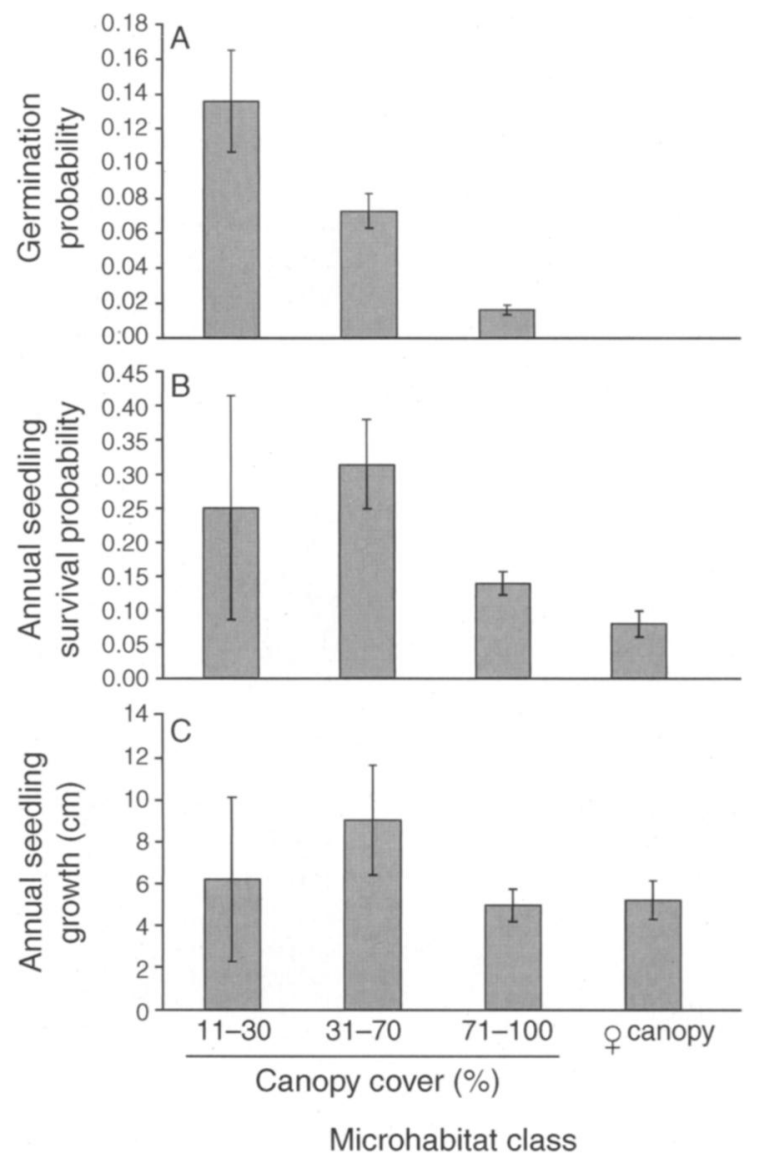

Fig. 2. (A) Germination ( $N=4200$ seeds), (B) seedling survivorship ( $N=1182$ seedlings), and (C) seedling growth $(N=$ 91 seedlings) across microhabitat types. Data are means $\pm \mathrm{SE}$.

\pm 0.005 for all three) (mean $\pm \mathrm{SD})$. The bootstrapped 95\% confidence intervals (see Fig. 3) of the 11-30\% canopy cover microhabitat did not overlap those of any other microhabitat; population growth was positive only in the 11-30\% canopy-cover microhabitat.

We then assessed how the three dispersers individually or together affected C. axillaris population growth (also see Appendix D). In a changing environment (i.e., canopy gaps forming and filling in) seed dispersal had only limited effects on $\hat{\lambda}$. The effects of dispersal are likely limited because unsuitable microhabitat for seed germination can turn into suitable microhabitat (i.e., gaps), causing seed dispersal under initially higher canopy covers to be sufficient in some instances. Under this scenario, dispersal by either gibbons or sambar (as opposed to no dispersal) had negligible effects, raising the tree's population growth rate $(\Delta \hat{\lambda})$ by a mean of 0.000 (95\% confidence interval [CI]: $0.000,0.001$ ), for both mammals. Only seed dispersal by muntjac raised the $C$. axillaris population growth rate significantly, by $0.005(95 \% \mathrm{CI}: 0.001,0.015)$; dispersal by all the frugivores combined raised $\Delta \hat{\lambda}$ by $0.004(95 \% \mathrm{CI}$ : $0.001,0.013)$. Adult survival followed by juvenile survival had the highest elasticities among the vital rates. Elasticities of fecundity, seed dispersal, seed predation, seedling survival, juvenile growth, and microhabitat transitions were roughly equal (Appendix E).

\section{DisCUSSION}

Despite a vast literature on zoochorous seed dispersal, studies that examine seed dispersal within the context of an entire plant's life cycle are still surprisingly rare (Howe and Miriti 2004, Godinez-Alvarez and Jordano 2007). Using this approach, we showed that Choerospondias axillaris demography is gap dependent. Similar to other tropical trees (Whitmore 1989), modeled $C$. axillaris population growth was positive only in microhabitats with relatively low canopy cover. Indeed the population on the Khao Yai (Thailand) forestdynamics plot may be declining $(\hat{\lambda}=0.989$; dispersal by all frugivores combined) because the overall forest is getting darker (increasing canopy cover), reducing the availability of high-light microhabitats. More importantly, against this backdrop of gap dependence, our results suggest that the three dispersers servicing $C$. axillaris do not have similar effects on the tree's population dynamics. Instead, muntjac deer appear to be the most important dispersers for $C$. axillaris primarily because they are the sole transporter of seeds (albeit rarely) to the most favorable, open-canopy environments. The $\Delta \hat{\lambda}$ confidence intervals for seed dispersal by muntjac do not overlap those for seed dispersal by gibbons or sambar deer, suggesting that they are significantly more effective mutualists for $C$. axillaris under these forest conditions. Gibbons and sambar have the same impacts on C. axillaris population dynamics. These results imply that not all frugivore species affect their shared host equivalently. In the absence of numerical or behavioral compensation by the other species, we estimate that loss of muntjac could have an order-of-magnitude greater impact on $C$. axillaris population dynamics than loss of gibbons or sambar (as measured by their mean $\Delta \hat{\lambda} s$ ).

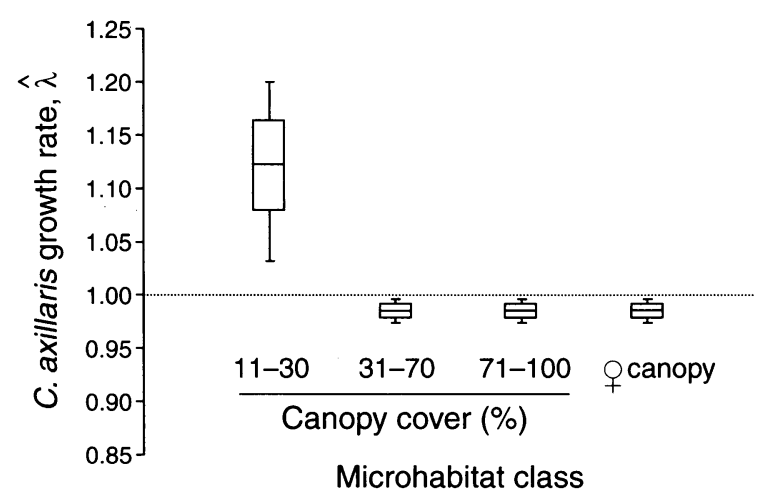

FIG. 3. Microhabitat-specific Choerospondias axillaris rate of population growth. Boxes and error bars show mean \pm SD and $95 \%$ bootstrap confidence intervals, respectively. 
The issue of behavioral or numerical compensation for the loss of muntjac, however, is not trivial. Clearly gibbons could not compensate for the loss of muntjac, since the former already have sole access to the fruits before they fall, and gibbons do not forage on the ground. Whether sambar abundance or foraging would change following removal of muntjac is unknown; studies in other systems have certainly demonstrated the plausibility of such compensation (Weins 1989, Renjifo 1999). Moreover, we documented the relative impacts of the three frugivores on C. axillaris demography in one habitat (seasonal forest) in a small part of the geographical range occupied by these four species. These impacts could very plausibly be significantly different in other areas or habitat types (Bronstein et al. 2003), or for other plant species.

In contrast to other studies that have found that the most effective dispersers (generally the largest-bodied species) are the first to be lost following excessive hunting (e.g., Peres 2000, Peres and Palacios 2007), muntjac in hunted forests in Thailand usually persist longer than either gibbons or sambar (J. F. Brodie, unpublished data). Gibbons are among the first mammals lost in over-hunted forests in Southeast Asia (J. F. Brodie, unpublished data) likely because of their sociality and conspicuous vocalizations (Brockelman and Srikosamatara 1993). Sambar are more social and much larger than muntjac, both factors that probably contribute to their increased vulnerability (Purvis 2001).

The positive role of deer in plant population dynamics is often overlooked since the seed-dispersal role of ungulates is generally thought to be overshadowed by their impacts as seedling predators (Russell et al. 2001, Horsley et al. 2003). Yet recent studies suggest that deer in temperate ecosystems may play important seeddispersal roles (Myers et al. 2004, Brathen et al. 2007, Eycott et al. 2007, Williams et al. 2008). Here we show that two deer species in the Asian tropics are also effective seed dispersers, one being the most important dispersal agent for a common and widespread canopy tree.

For such an abundant and prolifically fruiting tree, $C$. axillaris has remarkably few seed dispersers. Although the fruit pulp is clearly edible to primates (including humans) and ruminants, it may contain secondary compounds that deter other animals; phenolic allergens are common in the Anacardiaceae (Judd et al. 2002). The related and ecologically similar Spondias mombin of the Neotropics was thought be adapted for dispersal by gomphotheres (Pleistocene proboscideans; Janzen 1985). Yet, although modern Asian elephants are abundant in Khao Yai, we only found three $C$. axillaris seeds in elephant scat (two of which were crushed), despite thorough examinations of nearly 50 scat piles from 2003 through 2005. Other frugivores could possibly remove seeds to communal roosts (e.g., Pteropodid fruit bats) or latrines (e.g., civets), avoiding our detection on transects. However, only a small proportion of the seeds were unaccounted for; our estimation of the total number of seeds dispersed was actually slightly higher than the total number of seeds available on the forest dynamics plot (due either to measurement error or immigration of seeds from outside the plot; in the model the proportion of the total fruit crop on the plot that was dispersed could not exceed 1; see Fig. 1).

Gibbons, muntjac, and sambar differ both in where they deposit seeds and in the number of seeds they leave in deposition piles. Although deposition location clearly affects seed germination and seedling survival, the size of seed-deposition piles does not appear to play an important demographic role since germination and first-year seedling survivorship were not affected by seed-pile size. Moreover, due to overall low seedling survivorship across different-sized seed piles there was no evidence for density-dependent seedling mortality (cf. Russo and Augspurger 2007), even for seeds that germinated out of large deposition piles.

Neither secondary dispersal (further movement by animals of seeds that had already been dispersed once) nor seed dormancy appear to play a major role for $C$. axillaris. Although $30-40 \%$ of seeds are removed from their primary deposition locations, most do not travel more than $5 \mathrm{~m}$ (and are therefore unlikely to change microhabitats), and most are destroyed. We occasionally encountered caches of $C$. axillaris seeds in the forest, likely brought there by squirrels, but these were rare and, again, many of the seeds had been destroyed. Moreover, C. axillaris seeds must germinate within the year following their dispersal, otherwise they do not appear capable of germination; out of the 3350 seeds deposited in 2003 but that had not germinated by mid2004, none germinated by mid-2005.

The stage-structured population model we employed places differences in seed dispersal in an ecologically realistic context that includes demographic transitions as well as transitions in microhabitat state. We suggest that this approach may be generally useful for evaluating the population-level consequences of dispersal, especially for tropical trees that depend on abiotic disturbance for successful recruitment. We note, however, that our model makes several assumptions that may affect the robustness of its output. Perhaps most importantly, juvenile vital rates in our model are microhabitat independent. If juvenile growth or survival were actually strongly enhanced in canopy gaps, seed dispersal to gaps could be even more important than our results suggest. Moreover, as our seedling vital-rate measurements are based on two annual transitions, we cannot accurately assess variance in demography over time. Because $C$. axillaris is so highly benefited by canopy gaps, its longterm demography may depend on periodic cycles of intense forest disturbance by cyclones (W. Y. Brockelman, personal obsservation). To explore this possibility, we ran population models (as described in Methods: Population model, above) that simulated an intense storm every 10 years which sent $50 \%$ of the forest to the 
$0.11-0.30$ proportion canopy cover microhabitat without killing any $C$. axillaris individuals. Interestingly, even this extreme and unrealistically beneficial storm regime had little qualitative effect on estimated differences among frugivores in their impact on C. axillaris $\hat{\lambda}$ (see Appendix F). According to our model, the $C$. axillaris population we surveyed is slowly declining. This decline may be real; as noted, our microhabitat transition measurements suggest that the forest is getting darker over time (Appendix C), reducing the availability of light gaps where $C$. axillaris germination is enhanced. Alternatively, the apparent decline may be an artifact of the low sample sizes used to estimate the two highestelasticity vital rates, adult and juvenile survival. If six of the adults that died had instead survived, $C$. axillaris $\hat{\lambda}$ for the total dispersal scenario (all frugivores combined) would equal 1.00. The relative differences in $\Delta \hat{\lambda}$ for each frugivore, however, change only slightly; muntjac $\Delta \hat{\lambda}$ : gibbon $\Delta \hat{\lambda}$ and muntjac $\Delta \hat{\lambda}$ : sambar $\Delta \hat{\lambda}$ ratios both decline by $8.9 \%$.

The demographic importance of seed dispersal, and therefore the potential for differences in effectiveness among sympatric frugivores, is strongly affected by variation in tree life history. Although seed dispersal is statistically advantageous for $C$. axillaris demography in this population (the $\Delta \hat{\lambda}$ confidence intervals for muntjac dispersal did not overlap zero; see Fig. 4), its life history buffers it from variation in disperser effectiveness. Although seed dispersal to existing open microhabitats is beneficial for $C$. axillaris, even seeds initially deposited in the shade experience opportunities for success if the forest canopy opens above them. Moreover, C. axillaris seeds do not require ingestion in order to germinate. Thus the seed-removal component of dispersal is less important to $C$. axillaris than where the seeds end up. Other tree species, that either require seed scarification (Traveset 1998) or have lower seedling survival and are thus more dependent on immediate dispersal to sites favorable for germination (Bond 1995), tend to exhibit greater demographic reliance on seed dispersal (Bond 1995). As a result, these species may be more sensitive to functional differences among their attendant frugivores.

Combining models of microhabitat changes with plant demography may be a particularly useful approach for studying the population-level impacts of dispersers. In our case, this joint approach illustrated the pitfalls of estimating disperser impact solely by comparing how many seeds are dispersed by different animals. We found that sambar remove over twice as many seeds as gibbons, yet this does not result in stronger impacts on plant abundance, likely because many of the seeds that sambar ingest get "dispersed" right back under adult trees. This is in contrast to the general correlation reported between the visitation rate of a given frugivore species and its "total effect" on the plant (e.g., Vazquez et al. 2005, Bascompte et al. 2006). Likely this discrepancy is due to the above correlation assuming high variation in visitation rate that washes

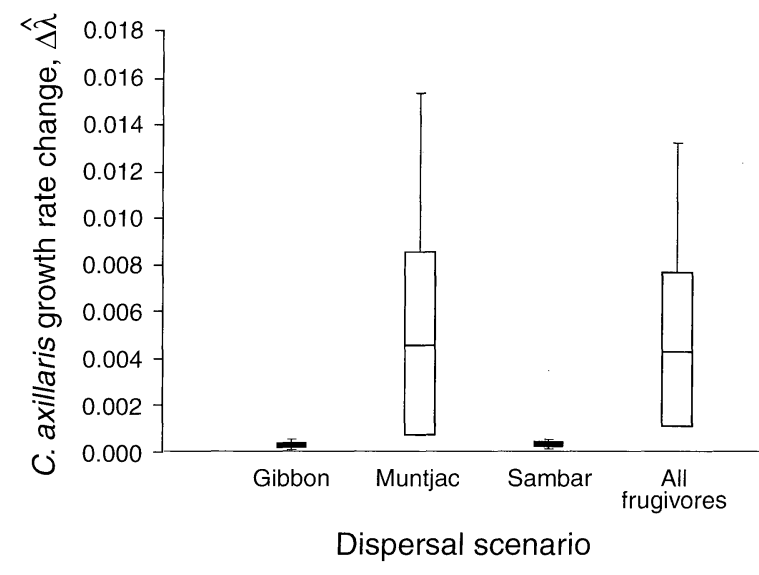

FIG. 4. Change in Choerospondias axillaris rate of population growth due to interaction with its seed dispersers; $\Delta \hat{\lambda}$ represents the change in lambda (population growth rate) when there is no seed dispersal compared to dispersal by each frugivore in isolation and all three combined. Boxes and error bars show mean \pm SD and $95 \%$ bootstrap confidence intervals, respectively (for muntjac and all frugivores, the lower error bar coincides with the lower $\mathrm{CI}$ ).

out smaller differences in frugivore effectiveness. In our system, variation in dispersal quality is large enough to outweigh differences in visitation rate. It is not clear why sambar may not disperse seeds far from parent trees whereas muntjac disperse seeds to microhabitats roughly in proportion to the availability of those microhabitats. We speculate that the disparity may be due to behavioral differences between the species (Russo et al. 2006). For example muntjac, unlike sambar, are territorial (Odden and Wegge 2007, Bagchia et al. 2008); perhaps their daily movement rates are higher as they patrol their home ranges. We suggest that our ability to accurately predict the ramifications of disperser loss will require studies that explicitly quantify and compare the relative impacts of frugivore species across habitats (Bronstein et al. 2003). Simple counts of individuals, or their visitation rates, may be insufficient to accurately assess the importance of particular dispersers in the same guild.

\section{ACKNOWLEDGMENTS}

We thank the Royal Forest Department and the National Research Council of Thailand, and the chief and staff of Khao Yai National Park. Funding for this project came from an EPA-STAR fellowship, NSF-DDIG grant, and Sigma Xi grant to J. F. Brodie, by the Denver Zoological Foundation, the Universities of Montana and Washington, and by grants to W. Y. Brockelman from the Biodiversity Research and Training Program, BIOTEC, Bangkok. J. L. Maron was supported by NSF grant OPP-296208. We thank E. Crone, L. S. Mills, R. Callaway, T. Martin, and two anonymous reviewers for very helpful critiques of the manuscript.

\section{Literature Cited}

Bagchia, S., S. P. Goyal, and K. Shankar. 2008. Social organisation and population structure of ungulates in a dry tropical forest in western India (Mammalia, Artiodactyla). Mammalia 72:44-49. 
Bascompte, J., and P. Jordano. 2007. Plant-animal mutualistic networks: the architecture of biodiversity. Annual Review of Ecology and Systematics 38:567-593.

Bascompte, J., P. Jordano, and J. M. Olesen. 2006. Asymmetric coevolutionary networks facilitate biodiversity maintenance. Science 312:431-433.

Bond, W. J. 1995. Assessing the risk of plant extinction due to pollinator and disperser failure. Pages 131-146 in J. H. Lawton and R. M. May, editors. Extinction rates. Oxford University Press, Oxford, UK.

Brathen, K. A., V. T. Gonzalez, M. Iversen, S. Killengreen, V. T. Ravolainen, R. A. Ims, and N. G. Yoccoz. 2007. Endozoochory varies with ecological scale and context. Ecography 30:308-320.

Brockelman, W. Y., and S. Srikosamatara. 1993. Estimation of density of gibbon groups by use of loud songs. American Journal of Primatology 29:93-108.

Bronstein, J. L. 1994. Conditional outcomes in mutualistic interactions. Trends in Ecology and Evolution 9:214-217.

Bronstein, J. L., W. G. Wilson, and W. E. Morris. 2003. Ecological dynamics of mutualist/antagonist communities. American Naturalist 162:S2-S39.

Christian, C. E. 2001. Consequences of a biological invasion reveal the importance of mutualism for plant communities. Nature 413:635-639.

Connell, J. H. 1971. On the role of natural enemies in preventing competitive exclusion in some marine animals and in rain forest trees. Pages 298-312 in P. J. Den Boer and G. Gradwell, editors. Dynamics of populations. Centre for Agricultural Publishing and Documentation, Wageningen, The Netherlands.

Cordeiro, N. J., and H. F. Howe. 2001. Low recruitment of trees dispersed by animals in African forest fragments. Conservation Biology 15:1733-1741.

Corlett, R. T. 1996. Characteristics of vertebrate-dispersed fruits in Hong Kong. Journal of Tropical Ecology 12:819 833.

Crouse, D. T., L. B. Crowder, and H. Caswell. 1987. A stagebased population model for loggerhead sea turtles and implications for conservation. Ecology 68:1412-1423.

Estrada, A., and T. H. Fleming. 1986. Frugivores and seed dispersal. Kluwer Academic Publishers, Dordrecht, The Netherlands.

Eycott, A. E., A. R. Watkinson, M. R. Hemami, and P. M. Dolman. 2007. The dispersal of vascular plants in a forest mosaic by a guild of mammalian herbivores. Oecologia 154 : $107-118$.

Figuerola, J., A. J. Green, and L. S. Santamaria. 2002. Comparative dispersal effectiveness for wigeongrass seeds by waterfowl wintering in south-west Spain: quantitative and qualitative aspects. Journal of Ecology 90:989-1001.

Forget, P.-M., and T. Milleron. 1991. Evidence for secondary seed dispersal by rodents in Panama. Oecologia 87:596-599.

Godinez-Alvarez, H., and P. Jordano. 2007. Seed dispersal by frugivores: an empirical approach to analyze their demographic consequences. Pages 391-406 in A. Dennis, R. Green, E. W. Schupp, and D. Wescott, editors. Frugivory and seed dispersal: theory and applications in a changing world. Commonwealth Agricultural Bureau International, Wallingford, UK.

Godinez-Alvarez, H., A. Valiente-Banuet, and A. RojasMartinez. 2002. The role of seed dispersers in the population dynamics of the columnar cactus Neobuxbaumia tetetzo. Ecology 83:2617-2629.

Gomulkiewicz, R., S. L. Nuismer, and J. N. Thompson. 2003 Coevolution in variable mutualisms. American Naturalist 162:S80-S93.

Horsley, S. B., S. L. Stout, and D. S. DeCalesta. 2003. Whitetailed deer impact on the vegetation dynamics of a northern hardwood forest. Ecological Applications 13:98-118.
Howe, H. F., and M. N. Miriti. 2004. When seed dispersal matters. BioScience 54:651-660.

Howe, H. F., and J. Smallwood. 1982. Ecology of seed dispersal. Annual Review of Ecology and Systematics 13. 201-228.

Howe, H. F., and G. A. Vande Kerckhove. 1981. Removal of wild nutmeg (Virola surinamensis) crops by birds. Ecology 62 . 1093-1106.

Janzen, D. H. 1970. Herbivores and the number of tree species in tropical forests. American Naturalist 104:501-528.

Janzen, D. H. 1985. Spondias mombin is culturally deprived in a megafauna-free forest. Journal of Tropical Ecology 1:131 155

Jordano, P. 1983. Fig-seed predation and dispersal by birds. Biotropica 15:38-41.

Jordano, P., C. Garcia, J. A. Godoy, and J. L. Garcia-Castano. 2007. Differential contribution of frugivores to complex seed dispersal patterns. Proceedings of the National Academy of Sciences (USA) 104:3278-3282.

Judd, W. S., C. S. Campbell, E. A. Kellogg, P. F. Stevens, and M. J. Donoghue. 2002. Plant systematics: a phylogenetic approach. Sinauer Associates, Sunderland, Massachusetts, USA.

Kunsakorn, P. 2001. Fruit production and seed dispersal of Choerospondias axillaris (Anacardiaceae) in Khao Yai National Park, Thailand. Thesis. Mahidol University, Bangkok, Thailand.

Lynam, A. J., P. D. Round, and W. Y. Brockelman. 2006. Status of large birds and mammals in Thailand's Dong Phayayen-Khao Yai forest complex. Biodiversity Research and Training Program and Wildlife Conservation Society, Bangkok, Thailand.

Morris, W. F., and D. F. Doak. 2002. Quantitative conservation biology. Sinauer Associates, Sunderland, Massachusetts, USA.

Myers, J. A., M. Vellend, S. Gardescu, and P. L. Marks. 2004 Seed dispersal by white-tailed deer: implications for longdistance dispersal, invasion, and migration of plants in eastern North America. Oecologia 139:35-44.

Ness, J. H., W. F. Morris, and J. L. Bronstein. 2006. Integrating quality and quantity of mutualistic service to contrast ant species protecting Ferocactus wislizeni. Ecology 87:912-921.

Odden, M., and P. Wegge. 2007. Predicting spacing behavior and mating systems of solitary cervids: a study of hog deer and Indian muntjac. Zoology 110:261-270.

Palmer, T. M., M. L. Stanton, and T. P. Young. 2003. Competition and coexistence: exploring mechanisms that restrict and maintain diversity within mutualist guilds. American Naturalist 162:S63-S79.

Palmer, T. M., M. L. Stanton, T. P. Young, J. R. Goheen, R. M. Pringle, and R. Karban. 2008. Breakdown of an antplant mutualism follows the loss of large herbivores from an African Savanna. Science 319:192-195.

Pascarella, J. B., and C. C. Horvitz. 1998. Hurricane disturbance and the population dynamics of a tropical understory shrub: megamatrix elasticity analysis. Ecology 79:547-563

Peres, C. A. 2000. Effects of subsistence hunting on vertebrate community structure in Amazonian forests. Conservation Biology 14:240-253.

Peres, C. A., and E. Palacios. 2007. Basin-wide effects of game harvest on vertebrate population densities in Amazonian forests: implications for animal-mediated seed dispersal. Biotropica 39:304-315.

Purvis, A. 2001. Mammalian life histories and responses of populations to exploitation. Pages 169-181 in J. D. Reynolds, G. M. Mace, K. H. Redford, J. G. Robinson, M. L. Gosling, G. Cowlishaw, R. Woodroffe, and J. Gittleman, editors. Conservation of exploited species. Cambridge University Press, Cambridge, UK. 
Reid, N. 1989. Dispersal of "mistletoes by honeyeaters and flowerpeckers: components of seed dispersal quality. Ecology 70:137-145

Renjifo, L. M. 1999. Effects of the landscape matrix on composition and conservation of bird communities. Dissertation. University of Missouri, St. Louis, Missouri, USA.

Russell, F. L., D. B. Zippin, and N. L. Fowler. 2001. Effects of white-tailed deer (Odocoileus virginianus) on plants, plant populations and communities: a review. American Midland Naturalist 146:1-26.

Russo, S. E., and C. K. Augspurger. 2007. Aggregated seed dispersal by spider monkeys limits recruitment to clumped patterns in Virola calophylla. Ecology Letters 7:1058-1067.

Russo, S. E., S. Portnoy, and C. K. Augspurger. 2006. Incorporating animal behavior into seed dispersal models: implications for seed shadows. Ecology 87:3160-3174.

Schupp, E. W. 1993. Quantity, quality and the effectiveness of seed dispersal by animals. Vegetatio 108:15-29.

Smitinand, T. 1977. Plants of Khao Yai National Park. New Thammada Press, Bangkok, Thailand.

Stanton, M. L. 2003. Interacting guilds: moving beyond the pairwise perspective on mutualisms. American Naturalist 162:S10-S23.
Traveset, A. 1998. Effect of seed passage through vertebrate frugivores' guts on germination: a review. Perspectives in Plant Ecology, Evolution and Systematics 1-2:151-190.

Traveset, A., and N. Riera. 2005. Disruption of a plant-lizard seed dispersal system and its ecological effects on a threatened endemic plant in the Balearic Islands. Conservation Biology 19:421-431.

Vazquez, D. P., W. F. Morris, and P. Jordano. 2005. Interaction frequency as a surrogate for the total effect of animal mutualists on plants. Ecology Letters 8:1088-1094.

Waser, N. M., L. Chittka, M. V. Price, N. M. Williams, and J. Ollerton. 1996. Generalization in pollination systems, and why it matters. Ecology 77:1043-1060.

Weins, J. A. 1989. The ecology of bird communities. Volume 2. Processes and variations. Cambridge University Press, Cambridge, UK.

Whitmore, T. 1989. Canopy gaps and the two major groups of forest trees. Ecology 70:536-538.

Williams, S. C., J. S. Ward, and U. Ramakrishnan. 2008. Endozoochory by white-tailed deer (Odocoileus virginianus) across a suburban/woodland interface. Forest Ecology and Management 255:940-947.

Yu, D. W., H. B. Wilson, and N. E. Pierce. 2001. An empirical model of species coexistence in a spatially structured environment. Ecology 82:1761-1771.

\section{APPENDIX A}

Structure of Choerospondias axillaris population projection matrix (Ecological Archives E090-048-A1).

\section{APPENDIX B}

Histogram of distances from dispersed seed piles to the nearest adult female Choerospondias axillaris (Ecological Archives E090048-A2).

\section{APPENDIX C}

Mean microhabitat transition matrix, $\mathbf{C}_{i j}$ (Ecological Archives E090-048-A3).

\section{APPENDIX D}

Mean Choerospondias axillaris projection matrices for each dispersal scenario (Ecological Archives E090-048-A4).

\section{APPENDIX E}

Sensitivy of Choerospondias axillaris population-growth rate (for all dispersers combined) to demographic vital rates (Ecological Archives E090-048-A5).

\section{APPENDIX F}

Assessment of storm impacts on the relative importance of seed dispersal to Choerospondias axillaris population dynamics (Ecological Archives E090-048-A6). 